\title{
Analysis on Standardization of Building Ceramic Raw Material Based on Manufacturability
}

\author{
Hubin Bai ${ }^{1}$, Ming Gong*, Kaifang Wang ${ }^{1}$ \\ ${ }^{1}$ China Building Material Test \& Certification Group(Shaanxi) Co. Ltd, Xi'an, Shaanxi, China, 710049 \\ *Quality Supervision and Inspection of Building and Sanitary Ceramics of Jiangxi Province, Gao An, Jiangxi, China, 330800
}

\begin{abstract}
Building ceramic consume a lot of mineral raw materials. The standardization of raw materials is the trend of ceramic industry. This paper analyzes the manufacturability of clay, quartz and feldspar, and their function in the ceramic production process, aims to provide some thoughts for the realization of raw material standardization, promotes the standardization of raw materials forward, improves the utilization rate of mineral raw materials and reduces environmental damage.
\end{abstract}

\section{Introduction}

According to statistics from the China Building \& Sanitary Ceramics Association, the output of building ceramics in 2019 is 10.161 billion $\mathrm{m}^{2}$. Calculated by $200 \mathrm{t} / 10,000 \mathrm{~m}^{2[1]}$, the equivalent output is 203.22 million tons. Even if the process loss is not considered, the consumption of ceramic raw materials has already been exceeded 200 million tons. The raw materials for building ceramic are mainly natural mineral raw materials. The standardization of raw materials can improve the utilization rate of mineral raw materials, protect limited resources and reduce environmental damage.

The physical properties, chemical properties and manufacturability of ceramic raw materials directly affect the quality of products. In the field of building ceramics, national standards for raw materials such as kaolin, talc, and zirconium silicate have been formulated, and industry standards for raw materials such as feldspar, and pyrophyllite have been formulated ${ }^{[2-4]}$, which has a demonstrative effect on the standardization of raw materials. These standards set requirements in terms of the appearance quality, chemical composition, moisture content, and particle size of the raw materials, and play an exemplary role in the standardization of raw materials. This article will analyze the manufacturability of three kinds of mineral raw materials of clay, feldspar, and quartz, interpret the standardization of raw materials, and promote the development of standardization of building and sanitary ceramics.

\section{Types of building ceramic materials}

According to the process characteristics, building ceramic raw materials are divided into four categories: plastic raw materials, barren raw materials, solvent raw materials and functional raw materials ${ }^{[5]}$. The main components and typical raw materials of these four types of raw materials are shown in Table 1.

Table1. :Four types of building ceramic raw materials

\begin{tabular}{|c|c|c|}
\hline Category & Main components & Main typical Raw Materials \\
\hline Plastic raw materials & $\mathrm{Al}_{2} \mathrm{O}_{3}, \mathrm{SiO}_{2}, \mathrm{H}_{2} \mathrm{O}$, etc & $\begin{array}{c}\text { Clay raw materials, such as: kaolin, bentonite, } \\
\text { etc. }\end{array}$ \\
\hline Barren raw materials & $\mathrm{SiO}_{2}, \mathrm{Al}_{2} \mathrm{O}_{3}, \mathrm{TiO}_{2}$, etc. & $\begin{array}{c}\text { Quartz raw materials, such as: quartz, } \\
\text { pyrophyllite, waste porcelain power, etc. }\end{array}$ \\
\hline Solvent-based raw materials & $\mathrm{K}_{2} \mathrm{O}, \mathrm{Na}_{2} \mathrm{O}, \mathrm{CaO}, \mathrm{Al}_{2} \mathrm{O}_{3}, \mathrm{SiO}_{2}$, etc. & $\begin{array}{c}\text { Feldspar raw materials, such as: feldspar, } \\
\text { limestone, dolomite, talc, etc. }\end{array}$ \\
\hline Functional raw materials & $\mathrm{ZnO}, \mathrm{ZrSiO}_{4}$, etc. & Zircon, pigments, etc. \\
\hline
\end{tabular}

It can be seen from Table 1 that the main components of plastic raw materials, barren raw materials and solvent raw materials all contain $\mathrm{Al}_{2} \mathrm{O}_{3}$ and $\mathrm{SiO}_{2}$. These two components form the basis of the building ceramic body.

\footnotetext{
* Corresponding author: 276805850@qq.com
} 
The unique components such as $\mathrm{K}_{2} \mathrm{O}$ and $\mathrm{Na}_{2} \mathrm{O}$ in raw materials play an irreplaceable role in the production.

\section{The manufacturability and function of raw materials}

The manufacturability of building ceramic raw materials is closely related to the mineral composition, chemical composition, and particle composition of the raw materials. In summary, the manufacturability of the raw materials includes plasticity, cohesiveness, dryness, sintering, expansibility, cohesiveness, consistency, thixotropy, etc. There are many types of building ceramic materials, and different materials have different functions and requirements in production.

For clay materials, high viscosity and plasticity can be obtained by adding more $\mathrm{Al}_{2} \mathrm{O}_{3}$. It is generally required that the content of $\mathrm{CaO}, \mathrm{MgO}, \mathrm{K}_{2} \mathrm{O}$ and $\mathrm{Na}_{2} \mathrm{O}$ in clay raw materials should be as small as possible, because these components will reduce the fire resistance of clay, shorten the range of sintering temperature, and cause green body foaming. The high content of $\mathrm{CaO}$ will affect the color surface.

For feldspar raw materials, it is required to contain as much $\mathrm{K}_{2} \mathrm{O}$ and $\mathrm{Na}_{2} \mathrm{O}$ as possible, and as few colored oxides as possible. There are also certain requirements for the content range of $\mathrm{SiO}_{2}$ and $\mathrm{Al}_{2} \mathrm{O}_{3}$. Generally, potash feldspar is widely used. This is because the melt viscosity of potash feldspar after melting is larger than that of albite, and the viscosity changes slowly with temperature, and the firing temperature range is also wide, which makes the product easy to be fired and prevents high temperature deformation.

For quartz raw materials, it is required that the content of $\mathrm{SiO}_{2}$ be high, the coloring oxides are low, and the amount of $\mathrm{Al}_{2} \mathrm{O}_{3}, \mathrm{CaO}, \mathrm{MgO}, \mathrm{K}_{2} \mathrm{O}$, and $\mathrm{Na}_{2} \mathrm{O}$ should be as little as possible to meet the requirements of the formula. If the content of $\mathrm{CaO}$ in the billet is too high, the billet will appear green, and the sintering temperature will be lowered, and make the formulation adaptability worse. If the content of Cao in glaze is too high, the fluidity of glaze will be reduced. Generally, quartz is used in grades in production, and the quartz raw materials for glaze should contain less colored oxides to ensure the whiteness of the glaze. The colored oxide of the quartz raw material for the blank can be slightly wider.

Functional raw materials can improve the glaze process of the raw materials without affecting the performance of the product. At present, most of the functional raw materials can be achieved standardized This article will not describe its manufacturability. The manufacturability of clay, quartz, and feldspar raw materials has important reference value for standardization.

\subsection{Clay raw materials}

Clay is a kind of hydrous aluminosilicate mineral with layered structure and fine particles. ${ }^{[6]}$ It is the main raw material of ceramics. Its manufacturability is the basic condition for stable ceramic production. Different types and origins of clay raw materials have different process characteristics. For example, bentonite is a high plasticity clay with more fine particles, showing strong viscosity, high molding moisture, large shrinkage and low sintering temperature, kaolinite clay has small particle dispersion, poor plasticity, high drying porosity, low drying strength, large sintering shrinkage and strong thixotropy.

In terms of product process, clay has two characteristics: one is to endow the clay with plasticity and sintering property to ensure the shaping of ceramic products. The combination of finely dispersed clay particles and barren raw materials can form a green body with a large bulk density, and has a certain dry green strength, which is conducive to the sintering of the products; the second is that the $\mathrm{Al}_{2} \mathrm{O}_{3}$ in clay is the main source of mullite during sintering. The existence and quantity of mullite crystals determine the performance of building ceramics.

\subsection{Quartz raw materials}

The main component of quartz is $\mathrm{SiO}_{2}$, and the raw ore is granular, white or off-grayish white. The main types of quartz are vein quartz, quartz sand, siliceous sandstone, quartzite, cryptocrystalline quartz, and amorphous quartz. The section of quartz has glass luster or fat luster, Mohs hardness is 7, and the relative density varies depending on the crystal shape. Quartz has strong acid resistance. Except hydrofluoric acid, all acids (including aqua regia) have no effect on it. When quartz contacts with alkaline substances, it can react to form soluble silicates, and react with alkali metal oxides at high temperatures to form silicates and glassy substances. The melting temperature range of quartz depends on the morphology and impurity content of silica.

Quartz raw materials play an important role in ceramic bodies and glazes. The effect of quartz on the process of ceramic body is mainly embodied in three aspects. One is to adjust the plasticity of the green body before firing, reduce the drying shrinkage of the green body, shorten the drying time and prevent the green body from deforming. Secondly when sintering, the expansion of quartz can partially offset the shrinkage of the green body. It can be dissolved in the liquid phase at high temperature and increase the viscosity of the melt, Undissolved quartz particles can form the skeleton of the green body and prevent the green body from softening and deforming. Thirdly, the distribution of quartz particles affects the strength of green body. In addition, quartz is the main component of the glass phase in ceramics. The presence of quartz in the glaze can improve the melting temperature and viscosity of glaze, reduce the thermal expansion coefficient of glaze, and affect the strength, hardness, wear resistance and chemical corrosion resistance of glaze layer.

\subsection{Feldspar raw materials}

Feldspar is an anhydrous aluminosilicate of alkali metals or alkaline earth metals, such as: potash feldspar, albite, anorthite, etc. The common feldspar minerals are mutually 
miscible minerals. As the solvent raw material in the ceramic blank, the melting characteristics of feldspar are related to the composition and impurity content. Generally, potash feldspar has a wide melting temperature range, albite has a low melting temperature and anorthite has a high melting temperature.

There are three aspects of feldspar raw materials in ceramic technology. Firstly, it can reduce the viscosity at normal temperature, shorten the drying time, reduce drying shrinkage and deformation. Secondly, at high temperature, it plays a role of fusing, forming viscous glass melt, providing alkali metal oxide, reducing the sintering temperature of green body. The dissolved part can accelerate the formation and development of mullite crystal, and endow the green body with certain mechanical strength and deformation Chemical stability.it Thirdly, feldspar is filled between crystalline particles after melting, which can increase the density of green body and reduce the gap, improve the electrical performance of ceramics and improve the transparency of products.

\section{Raw material processability and standardization}

The standardization of ceramic raw materials is through the fine production of raw materials, whose chemical composition, mineral composition, and particle composition are relatively stable and can only fluctuate within a certain range, so as to ensure the process performance of the raw materials and meet the needs of different users ${ }^{[7]}$ The raw material technological process includes mine exploration, raw material mining, stacking and aging, batching, homogenization, forming, testing and other processes. Standardization involves a wide range of aspects and involves many contents. The standardization of a single raw material is easy to achieve, and it is difficult to form a standardized system with multiple raw material that can meet the needs of different users. ${ }^{[8]}$ The manufacturability of the raw materials in this system is an important indicator. By analyzing the process properties of plastic raw materials-clay, barren raw material-quartz, solvent raw materials-feldspar, and combining with the characteristics of raw materials and composition of different producing areas, a systematic raw material standardization model is formed, which is conducive to promoting the development of building ceramic raw materials standardization.

The origin of ceramic raw materials is different, their formation age, geological age, genesis and surrounding environment are also different, so the composition and performance will also be very different, which will lead to a big difference in its manufacturability. Take kaolin as an example. The kaolin in the north is mostly of sedimentary type, and its chemical composition generally contains more $\mathrm{Al}_{2} \mathrm{O}_{3}, \mathrm{TiO}_{2}$ and organic matter. It has high viscosity, strong adsorption, and good plasticity. It is suitable for burning in an oxidizing atmosphere or a weak reducing atmosphere. ; The kaolin in the south is mostly formed by acid-resistant igneous rocks such as granite or hydrothermal alteration. The chemical composition has a higher content of $\mathrm{SiO}_{2}$ and $\mathrm{Fe}_{2} \mathrm{O}_{3}$, but a lower content of
$\mathrm{TiO}_{2}$ and organic matter. It has poor viscosity, weak adsorption, and poor plasticity, so it is suitable for firing in a reducing atmosphere. Therefore, when considering the standardization of raw materials, it is necessary to distinguish between the process differences of unified raw materials.

The manufacturability of raw materials is a systematic concept, and the chemical composition and compatibility of different raw materials need to be considered. Single raw material standardization is the basis of raw material standardization, stable manufacturability is a necessary condition for raw material standardization, rational formulation is the key to standardization, and accurate quality control methods are important tools. The ultimate goal of all work is to realize the production of high-quality, competitive prices and wide applicability of raw materials.

\section{Conclusion}

The quality of building ceramics is related to the physical properties, chemical properties, and manufacturability of raw materials. The standardization, serialization and specialization of raw materials are the development trend of ceramic industry. According to the standards of ceramic raw materials such as kaolin and talc, the physical properties, chemical properties and process properties of a single raw material can be tested and analyzed. However, there is still a long way to go to realize the standardized production of raw materials with reasonable proportioning, uniform distribution and stable processability. This article comprehensively analyzes the process performance of different raw materials, the main components and their interactions, and the influence of different components on the processability, and provides a direction that can be considered for establishing a systematic standardization model of ceramic raw materials.

\section{References}

1. China environmental protection standard.(2020) HJ 1096:2020 Technical guidelines of accounting method for pollution source intensity ceramics products manufacturing. http://www.mee.gov.cn/ywgz/fgbz/bz/bzwb/wrfzjszc /202002/W020200213577582814426.pdf.

2. Jinghong X. Boqing L. Youyin L. et.al.(2010) The current situation and development of raw material standards for building and sanitary ceramics. China Ceramics, Vol.46 No.12: 05-06

3. Yanzhen, L. (2015) On the standardization of ceramic raw materials and the protection of resources and environment. Ceramics, No 11:9-13.

4. Jun H, Zhuokun O. Feng T. et.al.(2012) Study on the Quality Control and Analytical Method of Ceramic Raw Material, Foshan Ceramics, Vol.22 No.3, 15-19

5. Xiaorong L.(2005) Ceramic technology, Hunan University Press, Changsha, Hunan.

6. Jifeng T. (2010).Raw materials. In Yangzhi, M.(Eds), Technical Manual of Modern Building Sanitary 
Ceramics. China Building Materials Industry Press, Beijing.16-42.

7. Zhaobin Z.(2014) Quality control and standardization of ceramic raw materials China High-Tech Enterprises,No.20:127-128

8. Liming G.(2006). Standardization of ceramic raw materials and commercialization of glaz.es and their development in my country. Journal of Ceramics. vol 27,No.1:103-106. 